\title{
Simulating 2008: A Mock Presidential Election's Impact on Civic Engagement
}

Janna L. Deitz, Western Illinois University

Keith Boeckelman, Western Illinois University

ABSTRACT Young adults have particularly low levels of civic engagement. Incorporating experiential learning activities as part of the political science curriculum shows promise to reverse this trend. We analyze the impact of a mock presidential election simulation on the civic engagement of college-aged students. Exit surveys of student participants and a oneyear follow-up survey confirm that this experiential learning activity had a positive effect on participants' levels of political knowledge, their interest in public life, and their attitudes about government in general.

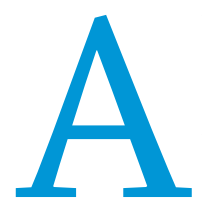

lthough colleges and universities have been centers for teaching and research about politics and government for centuries, their modern responsibilities include fostering a healthy democracy by promoting citizenship and political engagement, as well as knowledge (Colby et al. 2003; Colby et al. 2007; Harriger and McMillan 2007). Experiential learning opportunities, including simulations, are one specific approach that higher-education institutions can adopt to meet these goals (delli Carpini and Keeter 2000; Frederking 2005). In the realm of political science, research shows that out-of-class activities, even in introductory political science classes, stimulate political engagement (Chesney and Feinstein 1993). These techniques are especially effective when instructors integrate these with classroom instruction (Markus, Howard, and King 1993). Beaumont et al. (2006) have identified several "pedagogies of engagement" that are particularly likely to enhance students' political learning. These techniques include extensive student discussion or reflection, interaction with political figures as guest speakers, internships, service learning, and research or action projects.

This article describes and evaluates a specific instance of experiential learning: the Mock Presidential Election (MPE) simulation held in the fall of 2007 at Western Illinois University. Research on political simulations shows that these not only help students learn about political practices, but simulations also promote better understanding of political science theories (Hardy, Rack-

Janna L. Deitz is an associate professor of political science at Western Illinois University and was a 2011-12 APSA Congressional Fellow. Her research focuses on congressional elections, campaign finance, and women and politics. She can be reached at JL-Deitz@wiu.edu.

Keith Boeckelman is professor and chair of the department of political science at Western Illinois University. His research focuses on state politics and policy. He can be reached at KA-Boeckelman@wiu.edu. away, and Sonnier 2005). Furthermore, well-designed simulations can increase student empathy for elected officials and the challenges they face (Ciliotta-Rubery and Levy 200o). These also can help students overcome misconceptions about the political process, such as the tendency to underestimate the difficulty of achieving consensus in the political environment, or to overestimate the simplicity of public policy issues (Endersby and Webber 1995). Colby et al. (2007) argue that, in addition to the benefits listed previously, simulations and related activities build stronger political skills, motivate students to become more politically active, and reinforce larger academic goals related to the liberal arts curriculum. The upcoming 2012 presidential election presents another opportunity to teach students the values of civic engagement through electoral simulation. We share the details of how this process unfolded at one university and describe the impact this experience had on student civic engagement.

The next section describes the simulation. Then, we analyze learning outcomes based on two instruments: an exit survey taken at the time of the simulation and a follow-up survey one year later that compares students who participated in the simulation with a control group. The instruments include relevant measures of civic engagement, including political information, efficacy, and interest in politics. Finally, we discuss the implications of our findings regarding the use of simulations as a competency and skillbuilding tool for student civic engagement.

\section{THE MOCK PRESIDENTIAL ELECTION PROCESS}

Western Illinois University's MPE was a large-scale simulation of the presidential election process modeled after smaller-scale efforts conducted at the University of Iowa in 1976 and the University of Missouri in 1988. Taking place over five nights, in October and November 2007, MPE culminated in a general election session 
Table 1

\section{Mock Presidential Election Sequence of Events}

Session 1-Presidential Primaries and Caucuses/ Delegate Selection
Students are assigned to participate in the primaries and caucuses for particular states. When possible, their party preferences are taken into account. Students debate the merits of various candidates in their state groups and are exposed to campaign messages, speeches, etc. by the "mock" campaigns. At the end, students vote, publicly in subgroups in caucus states and by secret ballot in primary states. Delegates are assigned to competing candidates according to larger Democratic and Republican party rules regarding delegate apportionment.

Session 2-National Party Conventions/Keynote Speech and Platform Adoption

Democratic and Republican elected officials from the region are invited to give 15-20 minute keynote speeches laying out the party's basic principles. The platform contains 20 statements on current issues (e.g., same sex marriage, extension of Patriot Act, etc.). The statements are prepared in advance by MPE organizers. Party platform committees assign positions on a five-point scale from strongly oppose to strongly favor, and students debate and vote on whether to change party platform stance. A faculty member presides as party chair, assisted by another faculty member as parliamentarian.

Session 3-National Party ConventionsStudent representatives of "mock" campaigns give speeches on candidates' behalf. Students vote on presidential/vice presidential ticket.

Nominate Ticket for President/Vice President

Condensed version of Sessions 2 and 3 described above for Libertarian and Green parties. No primaries or caucuses are held for 3rd parties, but students debate and vote on platforms and presidential/vice presidential tickets.
Students are assigned to specific states. Representatives of remaining "mock" candidates give speeches and engage in other campaign activities. Students vote by state, and state results are tabulated and assigned electoral votes. Faculty and/or outside groups, such as the League of Women Voters, assist with vote tabulation. Winner of election is announced. that included more than 1,0oo participants. Table 1 describes the sequence of events during the five-night period.

Participants in the simulation were enrolled in political science and other courses, many at the introductory level. Most of the course sections were part of the university's First Year Experience (FYE) program, which provides entering college students with the opportunity to take small classes in a variety of disciplines. The initiative's emphasis, among other goals, is to promote engagement with the campus and larger communities outside of class; the goals of the FYE and MPE were intertwined. In addition, the connection to the FYE program ensured a broad crosssection of student participants.

Before the simulation began, organizers assigned students to a particular party, as well as to specific states that they would represent on different nights. During the first night, students were assigned to primary and caucus states, and they debated the virtues of the candidates running for the respective parties' nominations and were exposed to candidates' campaign materials. On the second night, students deliberated on party platforms and voted on issues ranging from gay rights to the war in Iraq. They also heard speeches from prominent state-level politicians laying out the respective parties' ideas. The third night featured speeches from students representing each candidate, followed by a vote on the parties' nominees. The respective winners were Obama and Edwards as the Democratic ticket, and Giuliani and McCain as the Republican standard bearers. The fourth night of the simulation featured compressed conventions for the Green and Libertarian parties. Finally, the simulation culminated with a replication of the general election, wherein students debated the merits of the nominees and cast the electoral votes for their states.

In addition to the standard roles of convention delegates and voters, students played a number of specialized roles. A select few were chosen to be campaign managers. These were upperlevel students (not necessarily political science majors) who served as spokespersons for their respective campaigns. Frequently, the campaign managers "appointed" assistant campaign managers, deputy campaign managers, volunteer coordinators, and communications directors. Several of the simulation managers and their assistants traveled to Iowa to meet campaign staff stationed there for the upcoming caucuses, discuss strategy, and obtain campaign materials to help inform their campaigns. These campaign workers held their own organizational meetings, publicized their candidates on campus, and engaged in GOTV efforts. Several students who worked on the MPE campaigns later volunteered for the actual presidential campaigns in Iowa.

Some students also participated in ways that were substantively connected to their own academic majors. For example, journalism students covered nightly events at the simulation. In another course, students prepared a daily publication, The NewsMeister, which reported on the previous night's activities and was distributed for free to all students on campus. Students in the broadcasting department simulated television coverage of the primary conventions and the general election night results.

The election simulation was designed to maximize student engagement in several ways. Extensive student discussion during the platform stage, which most students identified as their favorite part of the process, and the ability to interact with elected officials who gave keynote speeches embodied the "pedagogies of engagement" described by Beaumont et al. (2006). Moreover, several students engaged in de facto internships as part of the simulation. For example, one student recruited participants to be campaign workers and also served as mistress of ceremonies for the primary, caucus, and convention activities.

\section{MOCK PRESIDENTIAL ELECTION EXIT SURVEY RESULTS}

As noted earlier, two survey instruments measured the affect of the mock election. First, on the final night of the simulation, students completed the Mock Presidential Election Exit Survey. This one-page survey included basic demographic questions, measures 
of satisfaction, interest, and information as a result of participating in this electoral simulation. Of approximately 1,00o student participants, 889 students completed this survey at the conclusion of the simulation. Although the demographic profile of students engaged in this simulation is representative of college-aged students at four-year institutions, freshmen and sophomores are overrepresented. Due to the tie-in with the university's FYE program, underclassmen accounted for $69 \%$ of respondents.

The second survey 2008Presidential Election Survey was an online study the following year, which we discuss in the next section. It evaluated the long-term effects of participation in the simulation on various measures of civic engagement including voting, information gathering, and interest. Although the exit survey is more limited in scope, its results provides useful information regarding the efficacy of the event. These exit survey findings are discussed next, grouped into the following topics: satisfaction, information/competency, interest in campaigns and elections, and academic interest in political science. These areas highlight aspects of the simulation experience for students that should positively influence their future levels of civic engagement.

\section{Satisfaction}

Three questions on the survey asked students how satisfied they were with their participation in the event. Eighty percent of respondents indicated that the simulation was a positive event. More directly, when responding to the satisfaction question "Overall how satisfied are you with your Mock Presidential Election experience?" $88 \%$ indicated they were satisfied, with fully one-third of respondents indicating that they were "very satisfied." Only $12 \%$ of respondents indicated some level of dissatisfaction.

\section{Information/Competency}

Although satisfaction measures are standard components of most exit surveys, these may possibly gauge the entertainment value of the exercise in lieu of other more important indicators of knowledge, interest, or engagement. Primary learning outcomes for an election simulation certainly include learning more about the substance of the event and consequently feeling more comfortable in real-world political situations. The top of table 2 presents the descriptive findings for questions dealing with information and competency. Almost all respondents (93\%) reported that they felt more informed about the process of electing the president because of the simulation. Although a more direct measure might have been to administer an aptitude test on the subject, students' own self-reported measures provide a rough estimate that, at the very least, simulations like this help clarify the presidential election process. Surely, a first step toward civic involvement is to feel more confident and more informed about the process, and, by this measure, the simulation succeeded in meeting its intended goals. ${ }^{1}$

Five individual statements, with which students could agree or disagree, assessed how the simulation affected specific political competencies. These statements measured students' abilities to evaluate, comprehend, and form opinions about various aspects of politics; the results from these statements are presented in table 2. Sixty percent of respondents agreed with the statement that the Mock Presidential Election was useful in helping them "evaluate different theories and positions in American politics," while an additional $28 \%$ strongly agreed. Only $11 \%$ disagreed that the event was useful in this way. More than $80 \%$ of respondents reported that as a result of the simulation, they were better able to evaluate the utility and effectiveness of various political strategies. Students learned the rules and, more importantly, learned how to use them.

Understanding the complicated nature of the presidential selection process was probably the biggest hurdle for many students. Ninety percent agreed ( $31 \%$ of those strongly agreed) that the simulation helped them to understand election processes such as the Electoral College. Almost all respondents (92\%) indicated they were able to understand the main ideas presented by candidates, and perhaps more importantly, $89 \%$ indicated that, as a result of their participation in the simulation, they could form their own opinions on the main political issues involved in the campaign. These results suggest the utility of this simulation to provide opportunities for students to engage in critical thinking about real-world political events.

\section{Interest in Campaigns and Elections}

An additional measure of the civic efficacy of this simulation is indicated by the extent to which participation led to increased 
interest in campaigns and election-related activities. The bottom portion of table 2 presents exit survey responses to questions regarding interest in electoral politics. Threequarters of students expressed agreement that as a result of the simulation they were more interested in the campaigns and elections process. A total of $82 \%$ of respondents indicated that the simulation made them more likely to follow campaigns closely, with $28 \%$ of those expressing strong agreement.

Seventy-nine percent of students agreed that the simulation made them more likely to view campaigns more favorably. Despite the fact that "dirty tricks," like the maligning of opponent's campus posters, occurred in the simulation context, most students came away with a more favorable impression of the campaign process. Perhaps this is the result of the procedural knowledge they acquired and the resulting competency they reported in forming their own opinions on political issues and candidacies. ${ }^{2}$

Some students indicated that they would be more likely to become directly involved in civic and governmental affairs because of the activity. Of the respondents, $42 \%$ said they would be more likely to volunteer or intern for a campaign or government office. As expected, many students did not express an increase in active political involvement at this level ( $46 \%$ of students indicated the MPE did not make them more likely to volunteer or intern for a campaign or government office). However, 29\% indicated that their participation made them more interested in pursuing a career in politics. For many students, participating in the MPE increased their interest in civic affairs, and, for many of these students, that interest includes interning, volunteering, or running for office.

\section{Academic Interest in Political Science}

Around $30 \%$ of respondents indicated that the simulation had made them more interested in taking political science courses or more likely to continue majoring in the discipline. Most of the students participating in the simulation were neither political science majors nor taking political science coursework. As discussed earlier in this article, many students from different disciplines across campus participated in the event. Therefore, the simulation introduced some students to the study of American politics who might not otherwise be reached.

\section{FOLLOW-UP ANALYSIS: 2008 PRESIDENTIAL ELECTION SURVEY}

Although the exit survey results indicated that several key objectives of promoting civic education among MPE participants were met, a second one-year follow-up survey, conducted in October 2008, examined whether the positive effects suggested in the exit survey persisted for those students who participated in the election simulation. We included several questions on a broaderthemed 2008 Presidential Election Survey that was presented online to all students on campus. Students were asked if they had par- ticipated in the MPE, allowing for comparisons of simulation participants to nonparticipants. A total of 1,306 students completed this survey, and 205 (16\%) of those respondents had participated in the previous year's simulation. This comprehensive follow-up survey asked about various aspects of the 2008 presidential campaign ranging from standard questions regarding beliefs about individual candidates and issues facing the country to students' self-reported measures of knowledge, civic engagement, interest in politics/public affairs, and political efficacy. The results of selected questions are shown in table 3 .

Table 3 reports response percentages for simulation participants and nonparticipants and also provides chi-square values to assess the statistical significance of MPE participation on some indicators of political knowledge, interest, and engagement. As the table shows, more MPE participants than nonparticipants correctly answered questions relating to political processes, especially those questions that concerned procedures they experienced directly in the simulation. For example, more simulation participants (53\%) than nonparticipants (39\%) correctly identified where party platforms were developed, and this difference is statistically significant $\left(\chi^{2}=25.13, p<.001\right)$.

Additional aspects of the follow-up survey conducted in 2008 included measures of political interest and civic engagement. Students indicated their relative levels of interest in politics and public affairs using a scale that ranged from "not at all interested" to "very interested." The percentage of respondents who indicated that they were "somewhat interested" in politics and public affairs (30\% and 33\%) showed little change. However, at the upper end of the scale, more pronounced differences are noted, as shown in table 3. For example, $29 \%$ of nonparticipants indicated they were "very interested" in politics and public affairs, compared with $47 \%$ of simulation participants; the difference between these groups is statistically significant $\left(\chi^{2}=29.53, p<.001\right) .^{3}$ Indicators of civic engagement were also statistically significant. More students involved in the MPE indicated that they followed the presidential campaign "very closely" ( $\left.\chi^{2}=80.52, p<.001\right)$, and more of these participants stated they voted "very frequently" in student elections ( $\left.\chi^{2}=68.41, p<.001\right)$, which were held between the simulation and the follow-up survey, at a little more than twice the rate of nonparticipants. Questions about political efficacy, not shown in the table, revealed higher levels among MPE participants, but 
these differences were not significant. Overall, participation in the simulation appears to have had a positive effect on students' levels of political knowledge, interest, and engagement.

\section{CONCLUSION}

Simulations can successfully increase civic engagement of collegeaged students. Specifically, participants in Western Illinois University's 2007 Mock Presidential Election indicated higher levels of information and competency about the presidential election process, in addition to increased levels of political interest and civic engagement, when compared to nonparticipants. The process of the simulation itself acted as a civic skill-building tool for students, as some learned to speak in public, others learned to form and articulate their own political positions, and all learned the ins and outs of parliamentary procedure.

Admittedly, at times during the simulation we wondered if the level of technical detail would be beyond what students necessarily needed to know. Given the attention to the controversial role of super delegates in the Democratic Party during the 2008 campaign and the discussion of the democratic elements of primaries versus caucuses, however, the attention to detail in this simulation made it a more effective exercise in civic education. Looking back, this simulation proved remarkably prescient in its emphasis on the importance of rules and structure in the presidential election process.

Our one-year follow-up survey demonstrates that participating in the simulation had meaningful and significant effects in the way students viewed the political process and their attitudes about public life more generally. Our examination of the longerterm effects of this particular simulation suggests that these exercises effectively generate factual and procedural knowledge about a specific topic. The pedagogical outcomes for simulations can give students broader civic skills and competencies that may serve as the basis for increased civic engagement.

\section{NOTES}

1. Although not directly measured in the survey instrument, many anecdotal responses to the party platform and party convention nights were conveyed to faculty regarding how glad students were to "finally understand how this works"-and they were referring to parliamentary procedure. While not the main point of the simulation, knowing how to use parliamentary procedure is a useful skill that can be intimidating to students. There may be multiple learning opportunities in a simulation experience-possibly even ones civic educators may initially overlook.

2. This hypothesis is explored with the 2008 Presidential Election Survey conducted the following year.

3. This could result from a selection bias problem, whereby those students who are most interested in politics and public affairs were those most likely to participate in the simulation. Because the Mock Presidential Election drew its participants most heavily from Western Illinois University's First Year Experience program with its broad student base, however, selection bias is unlikely to explain this variation in interest in politics and public affairs.

\section{REFEREN CES}

Beaumont, Elizabeth, Anne Colby, Thomas Ehrlich, and Judith Torney-Purta. 2006. "Promoting Political Competence and Engagement in College Students: An Empirical Study." Journal of Political Science Education 2: 249-70.

Chesney, James D., and Otto Feinstein. 1993. "Making Political Activity a Requirement in Introductory Political Science Courses." PS: Political Science and Politics 26: $535-538$.

Ciliotta-Rubery, Andrea, and Dena Levy. 200o. "Congressional Committee Simulation: An Active Learning Experiment.” PS: Political Science and Politics 33: 847-51.

Colby, Anne, Elizabeth Beaumont, Thomas Ehrlich, and Josh Corngold. 2007. Educating for Democracy: Preparing Undergraduates for Responsible Political Engagement. San Francisco: Jossey-Bass.

Colby, Anne, Thomas Erlich, Elizabeth Beaumont, and Jason Stephens. 2003. Educating Citizens: Preparing America's Undergraduates for Lives of Moral and Civic Responsibility. San Francisco: Jossey-Bass.

Delli Carpini, Michael X., and Scott Keeter. 200o. "What Should Be Learned through Service Learning?” PS: Political Science and Politics 33: 635-37.

Endersby, James W., and David J. Webber. 1995. "Iron Triangle Simulation: A RolePlaying Game for Undergraduates in Congress, Interest Groups, and Public Policy Classes." PS: Political Science and Politics 27: 520-23.

Frederking, Brian. 2005. "Simulations and Student Learning." Journal of Political Science Education 1: 385-94.

Hardy, Richard J., Chapman Rackaway, and Laurie Sonnier. 2005. "In the Robes of the Supreme Court Justices: Critical Thinking through the Use of Hypothetical Case Law Analyses and Interactive Simulations." PS: Political Science and Politics 38: 411-14.

Harriger, Katy J., and Jill J. McMillan. 2007. Speaking of Politics: Preparing College Students for Democratic Citizenship through Deliberative Democracy. Dayton, $\mathrm{OH}$ Kettering Foundation Press.

Markus, Gregory, J. Howard, and David King. 1993. "Integrating Community Service and Classroom Instruction Enhances Learning: Results for an Experiment." Educational Evaluation and Policy Analysis 15: 410-19. 